\title{
The development of a clinical screening instrument for tumour predisposition syndromes in childhood cancer patients
}

\author{
Saskia M.J. Hopman ${ }^{\mathrm{a}}$, Johannes H.M. Merks ${ }^{\mathrm{a}}$, Corianne A.J.M. de Borgie ${ }^{\mathrm{b}}$, \\ Cora M. Aalfs ${ }^{c}$, Leslie G. Biesecker ${ }^{\text {d,e }}$, Trevor Cole ${ }^{\mathrm{f}}$, Charis Eng ${ }^{\mathrm{g}, \mathrm{h}}$, Eric Legius ${ }^{\mathrm{i}}$, \\ Eamonn R. Maher ${ }^{\mathrm{j}}$, Max M. van Noesel $^{\mathrm{k}}$, Alain Verloes ${ }^{1, \mathrm{~m}, \mathrm{n}}$, David H. Viskochil ${ }^{\mathrm{o}}$, \\ Anja Wagner $^{\mathrm{p}}$, Rosanna Weksberg ${ }^{\mathrm{q}, \mathrm{r}}$, Huib N. Caron ${ }^{\mathrm{a}}$, Raoul C.M. Hennekam ${ }^{\mathrm{s}, *}$
}

\footnotetext{
a Department of Paediatric Oncology, Emma Children's Hospital, Academic Medical Centre, Amsterdam, The Netherlands

${ }^{\mathrm{b}}$ Clinical Research Unit, Clinical Methodology, University of Amsterdam, The Netherlands

${ }^{\mathrm{c}}$ Department of Clinical Genetics, Academic Medical Centre, Amsterdam, The Netherlands

${ }^{\mathrm{d}}$ National Institutes of Health (NIH) Intramural Sequencing Centre (NISC), National Institutes of Health, Bethesda, USA

e National Human Genome Research Institute, NIH, Bethesda, USA

${ }^{\mathrm{f}}$ West Midlands Regional Genetics Service, Birmingham Women's Hospital, Birmingham, UK

${ }^{\mathrm{g}}$ Genomic Medicine Institute, Cleveland Clinic, Cleveland, OH, USA

${ }^{\mathrm{h}}$ Taussig Cancer Institute, Cleveland Clinic, Cleveland, OH, USA

${ }^{\text {i } C e n t r e ~ f o r ~ H u m a n ~ G e n e t i c s, ~ C a t h o l i c ~ U n i v e r s i t y ~ o f ~ L e u v e n, ~ L e u v e n, ~ B e l g i u m ~}$

${ }^{\mathrm{j}}$ Centre for Rare Diseases and Personalised Medicine, School of Clinical and Experimental Medicine, University of Birmingham, Birmingham, UK

${ }^{\mathrm{k}}$ Department of Paediatric Oncology, Sophia Children's Hospital, Erasmus Medical Centre, Rotterdam, The Netherlands

${ }^{1}$ Inserm, U676, Paris, France

${ }^{\mathrm{m}}$ Université Paris 7, Faculté de Médecine Denis Diderot, Paris, France

${ }^{n}$ AP HP, Hôpital Robert Debré, Service de Génétique Clinique, Paris, France

${ }^{\circ}$ Division of Medical Genetics, Department of Paediatrics, School of Medicine, University of Utah, Salt Lake City, USA

${ }^{\mathrm{p}}$ Department of Clinical Genetics, Erasmus Medical Centre, Rotterdam, The Netherlands

${ }^{\mathrm{q}}$ Department of Paediatrics, Division of Clinical and Metabolic Genetics, The Hospital for Sick Children, Toronto, Canada

${ }^{\mathrm{r}}$ The Institute of Medical Science, University of Toronto, Toronto, Canada

${ }^{\mathrm{s}}$ Department of Paediatrics, Emma Children's Hospital, Academic Medical Centre, Amsterdam, The Netherlands
}

\section{KEYWORDS}

Paediatric oncology Childhood cancer Screening instrument Tumour predisposition

\begin{abstract}
Background: Identification of tumour predisposition syndromes in patients who have cancer in childhood is paramount for optimal care. A screening instrument that can help to identify such patients will facilitate physicians caring for children with cancer. The complete screening instrument should consist of a standardised series of pictures and a screening form for manifestations not visible in the pictures. Here we describe the development of such a
\end{abstract}

* Corresponding author: Address: Department of Paediatrics, Emma Children's Hospital, Floor H7, Room 236, Academic Medical Centre, Meibergdreef 9, 1105 AZ Amsterdam, The Netherlands. Tel.: +31 20 5668844; fax: +31 205669683.

E-mail address: r.c.hennekam@amc.uva.nl (R.C.M. Hennekam).

0959-8049/\$ - see front matter (C) 2013 Elsevier Ltd. All rights reserved. http://dx.doi.org/10.1016/j.ejca.2013.06.015 


\section{syndromes}

Delphi process

Questionnaires screening form based on an international two-stage Delphi process and an initial validation of the complete instrument.

Patients and methods: We identified manifestations that may contribute to the diagnosis of a tumour predisposition syndrome through the Winter-Baraitser Dysmorphology Database and the textbook "Gorlin's Syndromes of the Head and Neck". In a two-round Delphi process, eight international content-experts scored the contribution of each of these manifestations. We performed a clinical validation of the instrument in a selected cohort of 10 paediatric cancer patients from another centre.

Results: In total, 49 manifestations were found to contribute to the diagnosis of a tumour predisposition syndrome and were included in the screening form. The pilot validation study showed that patients suspected of having a tumour predisposition syndrome were recognised. Excellent correlation for indications of patient's referral between the screening instrument and the reference standard (personal evaluation by an experienced clinical geneticist) was found. Conclusions: The Delphi process performed by international specialists with a function as opinion leaders in their field of expertise, has led to a screening instrument for childhood cancer patients. Patients who may have a tumour predisposition syndrome and thus have an indication to be referred for further genetic analysis, can be identified using the screening instrument.

(c) 2013 Elsevier Ltd. All rights reserved.

\section{Introduction}

The diagnosis of a specific tumour predisposition syndrome in patients with childhood cancer is important and clinically relevant because it can affect management. Some syndrome-associated malignancies require specific treatment strategies and some require screening for subsequent malignancies. Also, it may guide care for non-malignancy manifestations; it facilitates recurrence risk assessments and can facilitate pre-symptomatic identification of other relatives at risk for malignancies.

In previous studies, we found a substantial incidence of morphological abnormalities and recognisable clinical genetic syndromes in patients with childhood cancer. Half of these syndromes had not been recognised by the routine caregivers involved, despite expert paediatric care. $^{1-3}$ We and others recommended that all children diagnosed with a malignancy should be assessed by a clinical geneticist or a paediatrician skilled in clinical morphology. ${ }^{2,4,5}$ However, in many countries there is limited access to such consultations and genetic consultations can be a low priority in acutely ill patients. A screening instrument could be a reliable aid in assuring that all childhood cancer patients at risk of having a tumour predisposition syndrome can be recognised and referred.

We argue that an easy-to-use screening form together with a standard series of $2 \mathrm{D}$ and $3 \mathrm{D}$ pictures could serve as a screening instrument. The form should easily be completed by a genetic nurse or physician involved in treatment of paediatric cancer patients. This would allow for a quick, efficient screen of completed forms accompanied by corresponding sets of pictures by a clinical geneticist who can then select those suspected to have a syndrome for a full genetic consultation. Such a screening form should be based on manifestations of known tumour predisposition syndromes, as these manifestations have already shown to indicate the cancer susceptibility. The number of tumour predisposition syndromes is large, which would result in a significant number of individual manifestations making a "non-focused' form unfeasible. Therefore, it is important to extract the most significant manifestations.

Part of the manifestations in tumour predisposition syndromes will be visible on a standard set of twodimensional (2D, overview; face in two directions; hands; feet) and three-dimensional (3D) pictures (face). The goal of this study was to identify the most sensitive manifestations of known tumour predisposition syndromes, not visible on these pictures, to include these in a screening form.

\section{Patients and methods}

\subsection{General strategy}

Two important sources for the manifestations of tumour predisposition syndromes were used; a database (Winter-Baraitser Dysmorphology Database [WBDD]) ${ }^{6}$ and a textbook (Gorlin's Syndromes of the Head and Neck). ${ }^{7}$ The recently published set of standardised terms to describe human morphology was used in the definite screening form. ${ }^{8-14}$

\subsection{Expert-based opinion/Delphi process}

We used a two-phase Delphi process ${ }^{15,16}$ in which eight international specialists in this field participated. The Delphi technique is a widely accepted method for achieving convergence of opinion from experts. It is used as a method for consensus-building using a series of questionnaires in multiple consultation rounds to collect data from a panel of experts, where evidence from literature is lacking. ${ }^{15}$ In the present study we interrogated the expert-panel regarding manifestations that 
only can be found in body surface examination and their contribution to the diagnosis of a tumour predisposition syndrome. In the first assessment round, eight experts gave their opinion on the relevance of the morphological manifestations from the sources WBDD and Gorlin's Syndromes of the Head and Neck. Relevance was defined as the significance or contribution of that manifestation to establishing a diagnosis of a tumour predisposition syndrome. Experts were asked to score the relevance of a manifestation on a scale from 1 to 5 (Likert scale) in which 1 was no contribution to the diagnosis of a tumour predisposition syndrome and 5 was pathognomonic for the diagnosis of a tumour predisposition syndrome. In the second assessment round, the same eight experts gave their final opinion on whether manifestations should be included in the screening form or not using a dichotomic score (in which $0=$ exclude, $1=$ include in screening form).

The strategy of the Delphi process is provided in Figs. 1 and 2. In Supplementary data 1 more detailed information on search strategy and item selection (S1.1), search terms used (S1.2) visibility score of manifestations (S1.3) and details of the Delphi process (S1.4) are given.

\subsection{Pilot validation study}

The list of selected manifestations based on both Delphi rounds was converted to a clinical scoring form, to which was added space for relevant general data. At this stage, WBDD nomenclature was harmonised with the Elements of Morphology terms ${ }^{8-14}$ (Supplementary data 4, S4.1). To aid users, a booklet was composed with definitions and pictures of included manifestations (Supplementary data 4, S4.2).

An initial clinical validation was performed using a cohort of 10 selected paediatric cancer patients under care of another centre, who had a standard evaluation by a clinical geneticist not involved in the development of the screening instrument (A.W.). This cohort was composed of patients suspected to have a tumour predisposition syndrome and those not suspected to have this. The study protocol was approved by the Medical Ethics Review Committee of the Academic Medical Centre in Amsterdam. All patients and parents gave their written informed consent. Specifically for the validation process of the screening instrument an independent genetic counsellor (nurse specialised in clinical genetics) evaluated every patient and filled in the scoring form for each patient, which was complemented with the $2 \mathrm{D}$ and $3 \mathrm{D}$ picture series. Two independent clinical geneticists from another centre, one with specific expertise in dysmorphology (R.C.M.H.) and one with specific expertise in oncogenetics (C.M.A.), neither of whom had been in contact with the patients, evaluated for each patient the set of pictures and completed scoring form from the screening instru- ment. Based on the completed screening instrument they assessed whether referral to a clinical geneticist was indicated and classified the reason for referral (i.e. history of the patient; tumour type; family history; phenotype; or any combination of the above). Combined outcomes of both observers were compared to the reference standard: the state of the art evaluation provided by the experienced local clinical geneticist (A.W.).

\section{Results}

\subsection{Identification of tumour predisposition syndromes}

Using search terms based on the paediatric cancer classification system ICCC3 (International Classification of Childhood Cancer) (Supplementary data 1, S1.1), 460 potential syndromes were identified in the WBDD. Selection for those syndromes in which the abstract in the WBDD reported indeed an association with malignant conditions yielded 194 definite tumour predisposition syndromes. The search in the textbook 'Gorlin's Syndromes of the Head and Neck' (Supplementary data 1, S1.2) yielded 27 additional tumour predisposition syndromes. Collection of all morphologic manifestations of these 221 included tumour predisposition syndromes (Supplementary data 1, S1.5) according to WBDD systematic yielded 335 manifestations. After exclusion of 95 manifestations that were visible on the 2D and 3D picture series, 240 morphological manifestations remained upon which to collect expert-based opinions (Fig. 1).

\subsection{Delphi round one}

Decisive agreement for inclusion (median score $\geqslant 4.5$, interquartile range (IQR) $4-5$ ) in the screening form was achieved for five manifestations $(5 / 240,2 \%)$ in the first round: abnormal genital pigmentation, adenoma sebaceous, axillary freckles, conjunctival teleangiectasia, neurofibromas/schwannomas.

Agreement for exclusion (median score $\leqslant 2$, range 1-5) was achieved for 181 manifestations (181/240, 75\%). For 54 manifestations $(54 / 240,23 \%)$ agreement was neutral $(2<$ median $<4.5$, range $1-5)$ and these manifestations were brought to the second round of the Delphi process.

Based on personal experience, the experts added 41 manifestations in the first round. Using the criteria as described earlier (manifestations found by body surface examination only or proposed by more than one expert), 7/41 manifestations were brought to the second round of the Delphi process as a separate dataset (Supplementary data 2, Table S2.2).

\subsection{Delphi round two}

In the second assessment round, the same eight experts gave their final opinion on whether $61(54+7)$ 


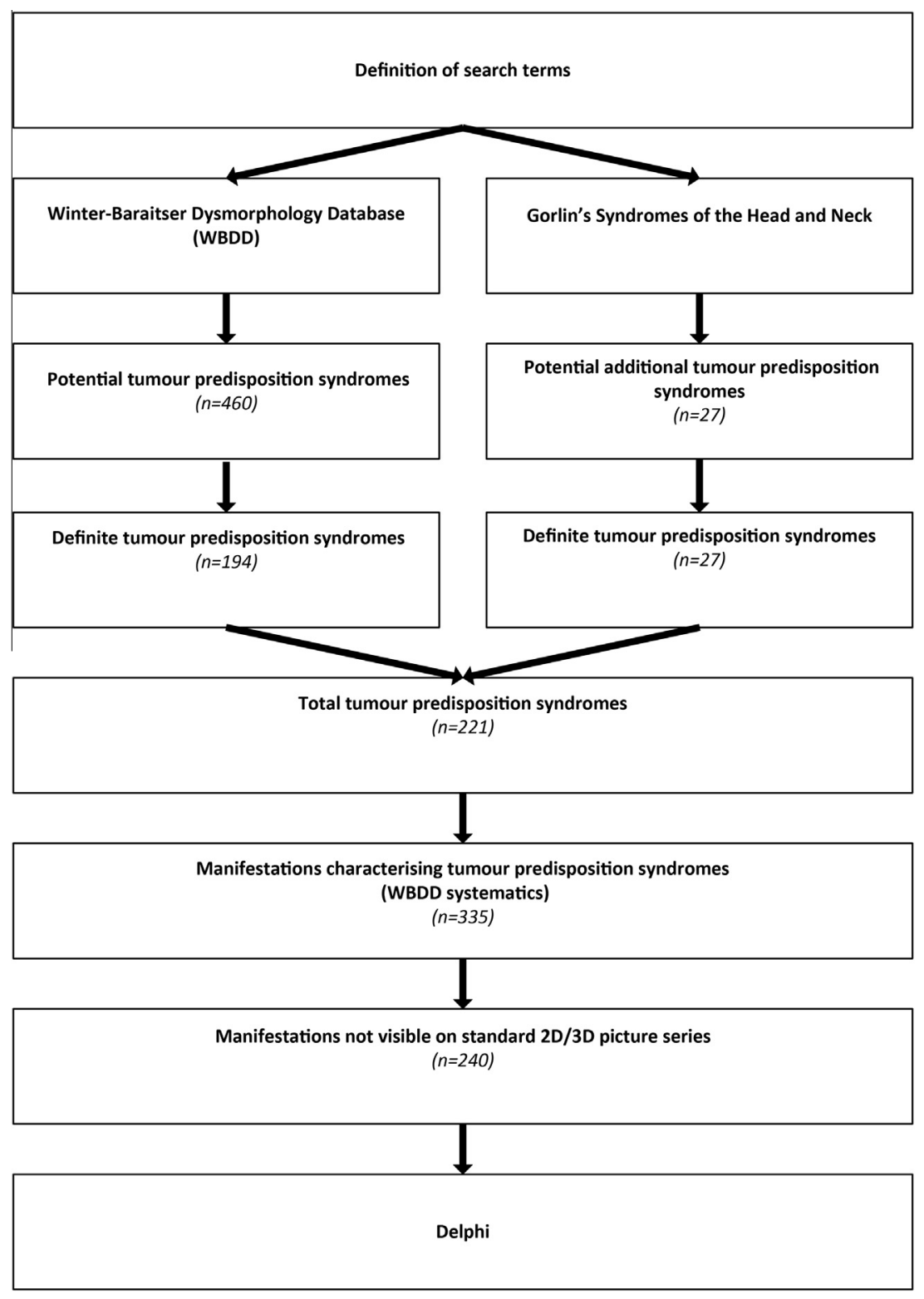

Fig. 1. Identification of tumour predisposition syndromes, search strategy and item selection.

manifestations should be included in the screening form or not. Agreement for inclusion was achieved for 41 manifestations $(41 / 61,67 \%)$.

The whole group of experts scored unanimous for 14 of the included manifestations (14/41, 34\%). For 27 manifestations $(27 / 41,66 \%)$, the majority of experts favoured inclusion. Agreement for exclusion was achieved for 13 manifestations $(13 / 61,21 \%)$, the agreement of seven manifestations $(7 / 61,11 \%)$, was non-decisive. Of these non-decisive, three were included based on the principal investigator's assessment. Thus a total of 44 items $(44 / 61,72 \%)$ were included in the second Delphi round (Supplementary data 2, Table S2.3). Together with the five manifestations that were selected in the first round, 49 definitive clinical manifestations (Table 1) were included in the screening form. In
Supplementary data 4 both the screening form and the accompanying definitions and pictures are shown.

\subsection{Pilot validation study}

The considered opinions of three senior clinical geneticists, on the need and indication of referral were compared in a selected cohort of 10 paediatric cancer patients. Need for referral and the reasons for referral were independently assessed based on a routine clinical genetic consultation by one geneticist and on the use of the developed screening instrument by two other geneticists.

The geneticist that judged based on the routine consultation found an indication of referral ('suspect for having a tumour predisposition syndrome') in six 




Fig. 2. Expert-based opinion, Delphi method.

patients, the two that judged based on the screening instrument found an indication of referral ('suspect for having a tumour predisposition syndrome') in seven patients (Table 2). The reasons for referral as result of the routine consultation were also selected by the geneticists using the screening instrument. The geneticists using the instrument deduced more reasons for referral than the geneticist that judged based on the regular consultation.

\section{Discussion}

The development of a descriptive screening form is reported, and its application in a pilot study. It is anticipated that physicians or genetic nurses caring for chil- dren with cancer can easily fill out the form for each child. Completed forms accompanied by corresponding sets of pictures can then quickly and efficiently be evaluated for the need for a full genetic consultation by a clinical geneticist.

Because available evidence on prevalence and recognition of tumour predisposition syndromes in patients with childhood cancer is scarce, ${ }^{1,2}$ the value of the expert opinions elicited in the Delphi process reflects and values the clinical consensus of these international opinion leaders in their field. One of the major benefits of the Delphi method is that it offers the opportunity to obtain expert opinions without potential influence of group dynamics on individual opinions. Because we chose to give feedback on the scores anonymously, experts could 
Table 1

All manifestations included in the screening form, ordered by Winter-Baraitser Dysmorphology Database (WBDD) systematic.

\begin{tabular}{|c|c|c|}
\hline WBDD category & Manifestation & Inclusion Delphi round \\
\hline Abdomen & Umbilical hernia & 2 \\
\hline Cranium & Macrocephaly & 2 \\
\hline Cranium & Microcephaly & 2 \\
\hline Cranium & Scalp tumours & 2 \\
\hline Ears & Crease/pits of ear lobule & 2 \\
\hline Ears & Pits of ear helix & 2 \\
\hline Ears & Posterior helical pits & 2 \\
\hline Endocrine & Ectopic/enlarged thyroid & 2 \\
\hline Eyes, globes & Cataract & 2 \\
\hline Eyes, globes & Conjunctiva telangiectasia & 1 \\
\hline Eyes, globes & Visible nerve fibres on cornea & 2 \\
\hline Genitalia & Abnormal genital pigmentation & 1 \\
\hline Genitalia & Ambiguous/absent genitalia & 2 \\
\hline Genitalia & Early puberty in females & 2 \\
\hline Genitalia & Early puberty in male & 2 \\
\hline Genitalia & Female pseudohermaphroditism & 2 \\
\hline Genitalia & Male pseudohermaphroditism & 2 \\
\hline Genitalia & True hermaphroditism & 2 \\
\hline Hair & Brittle hair & 2 \\
\hline Hands ${ }^{I I}$ & Palmar pits & 2 (added by expert panel) \\
\hline Leukoplakia & Leukoplakia & 2 \\
\hline Lower limbs & Asymmetric lower limbs ${ }^{\mathrm{I}}$ & 2 \\
\hline Lower limbs & Hypertrophy of lower limb ${ }^{\mathrm{I}}$ & 2 \\
\hline Neurology & Ataxia & 2 \\
\hline Neurology & Cranial nerve palsies & 2 \\
\hline Nose & Nasal telangiectasia & 2 \\
\hline Oral region & Large tongue & 2 \\
\hline Oral region & Lobulated tongue (including hamartomata) & 2 \\
\hline Oral region & Oral pigmentation & 2 \\
\hline Oral region & Oral tumour & 2 \\
\hline Oral region & Protruding tongue & 2 \\
\hline Oral region $^{\mathrm{II}}$ & Abnormal oral mucosa (cobblestone) & 2 (added by expert panel) \\
\hline Oral region ${ }^{\mathrm{II}}$ & Mucosal neurinomas & 2 (added by expert panel) \\
\hline Oral region $^{\mathrm{II}}$ & Papilloma periorifical & 2 (added by expert panel) \\
\hline Skeletal & Hemi-hypertrophy ${ }^{\mathrm{I}}$ & 2 \\
\hline Skin & Adenoma sebaceous & 1 \\
\hline Skin & Axillary freckles & 1 \\
\hline Skin & Lipomata & 2 \\
\hline Skin & Neurofibromas/schwannomas & 1 \\
\hline Skin & Pedunculated skin lesions/skin tags & 2 \\
\hline Skin ${ }^{I I}$ & Photosensitivity skin & 2 (added by expert panel) \\
\hline Skin & Thin skin/generalised skin atrophy & 2 \\
\hline Skin & Teleangiectasia & 2 \\
\hline Skin ${ }^{\text {II }}$ & Blue naevi & 2 (added by expert panel) \\
\hline Skin ${ }^{I I}$ & Hyperpigmentation & 2 (added by expert panel) \\
\hline Stature & Short stature, proportionate & 2 \\
\hline Stature & Tall stature, proportionate & 2 \\
\hline Thorax & Supernumerary nipples & 2 \\
\hline Upper limbs & Asymmetric arms & 2 \\
\hline
\end{tabular}

I: During the Delphi procedure the original terminology as used in the WBDD was maintained. For the definite screening form, terms were harmonised with the Elements of Morphology terms. ${ }^{8-14}$

II: These items were added by the experts and are not part of the WBDD systematic; categories were assigned by the investigators.

see their own opinion in relation to that of other experts, making it a safe, non-judgmental environment for sharing one's opinion. Because the time frame of response was defined and standardised, this assessment gave a good reflection of the current opinion in the field of expertise at a given time point, making it more reliable.

Because all opinions were weighed equally, an assumption was that the experts participating in the Delphi process were equal in experience and knowledge.
However, this may not have been the case, especially if their fields of expertise were very specialised, as in our study. For our expert panel, we chose international clinical geneticists who functioned as opinion leaders in both dysmorphology and clinical cancer genetics, or are leaders in one of the two with good experience in the other field. The number of qualified experts was relatively small, which restrained the number of experts in our panel. The small size of the expert panel could be 
Table 2

Overview of the patients from the validation cohort, the judgments of the three clinical geneticists (CG1, CG2, CG3) on the indication of referral and the reason(s) for referral.

\begin{tabular}{|c|c|c|c|c|c|c|c|}
\hline Patient & Tumour & $\begin{array}{l}\text { Judgment based } \\
\text { on regular } \\
\text { consultation } \\
\text { CG1 }\end{array}$ & $\begin{array}{l}\text { Reason referral } \\
1 / 2 / 3 / 4^{*} \text { based } \\
\text { on regular } \\
\text { consultation }\end{array}$ & $\begin{array}{l}\text { Judgment based } \\
\text { on screening } \\
\text { instrument } \\
\text { CG2 }\end{array}$ & $\begin{array}{l}\text { Reason referral } \\
1 / 2 / 3 / 4^{*} \text { based } \\
\text { on screening } \\
\text { instrument }\end{array}$ & $\begin{array}{l}\text { Judgment based } \\
\text { on screening } \\
\text { instrument } \\
\text { CG3 }\end{array}$ & $\begin{array}{l}\text { Reason referral } \\
1 / 2 / 3 / 4^{*} \text { based } \\
\text { on screening } \\
\text { instrument }\end{array}$ \\
\hline 1 & $\begin{array}{l}\text { Neurofibroma } \\
\text { prostate }\end{array}$ & Referral & $(2), 4$ & Referral & 2,4 & Referral & $2,(4)$ \\
\hline 2 & Hepatoblastoma & Referral & 2 & Referral & 2,3 & Referral & 2,3 \\
\hline 3 & Wilms tumour & No referral & NA & No referral & NA & Referral & 4 \\
\hline 4 & $\begin{array}{l}\text { Hodgkin } \\
\text { lymphoma }\end{array}$ & Referral & 4 & Referral & 1,4 & Referral & $1,3,4$ \\
\hline 5 & $\begin{array}{l}\text { Hodgkin } \\
\text { lymphoma }\end{array}$ & No referral & NA & No referral & NA & No referral & NA \\
\hline 6 & Wilms tumour & Referral & $1,(4)$ & Referral & 1,4 & Referral & $1,(3)$ \\
\hline 7 & Dysgerminoma & Referral & 2 & Referral & 2 & Referral & 2 \\
\hline 8 & $\begin{array}{l}\text { Acute } \\
\text { Lymphoblastic } \\
\text { Leukaemia }\end{array}$ & No referral & NA & No referral & NA & No referral & NA \\
\hline 9 & $\begin{array}{l}\text { Adrenal cortical } \\
\text { carcinoma }\end{array}$ & Referral & 2 & Referral & 2,4 & Referral & 2 \\
\hline 10 & $\begin{array}{l}\text { Burkitt } \\
\text { lymphoma }\end{array}$ & No referral & NA & Referral & 2,4 & No referral & NA \\
\hline
\end{tabular}

$1=$ patient's history related, $2=$ tumour related, $3=$ family history related, $4=$ morphological examination related.

$\mathrm{NA}=$ not applicable, $\mathrm{CG} 1=$ clinical geneticist $1, \mathrm{CG} 2=$ clinical geneticist $2, \mathrm{CG} 3=$ clinical geneticist 3.

considered as a potential limitation in the current study. However we feel that, considering the small field of study, the expert panel optimally represents international expert opinions. Other Delphi studies with similar sized expert panels have shown to yield reliable results. ${ }^{17,18}$

In the present Delphi process we had to define criteria on when to include, exclude or bring a manifestation to the next Delphi round. For the first round of the Delphi we used the median scores of experts for each manifestation for inclusion and exclusion, as the median is less affected by outliers which is especially important in small groups, ${ }^{15}$

We used a strict exclusion (median $\leqslant 2$ ) and inclusion criterion (median $\geqslant 4.5$ ) on the scale from 1 to 5 in the first Delphi round, so only items with strong agreement among the experts were included or excluded.

We performed a pilot validation study in an independent series of 10 paediatric cancer patients and compared the clinical judgment and rationale for referral by two independent clinical geneticists using the instrument, to those of a third clinical geneticist who evaluated the patients in routine consultations. In the pilot validation study, the clinical judgments of the two clinical geneticists using the screening instrument were very similar despite their different specialisation (dysmorphology versus oncogenetics). Furthermore, this was not a randomly selected patient cohort; the cohort in this clinical validation study consisted of both patients suspected as well as patients unsuspected of having a tumour predisposition syndrome which could give rise to selection bias. In our pilot validation study, a genetic counsellor (genetic nurse) filled in the screening form; we do not expect a significant difference if the form were filled in by a paediatric oncologist or other physician involved in the care of childhood cancer patients, although this was not tested.

We have not added criteria for referral indications for each tumour type and family history on our screening form: establishing reliable algorithms for the large range of tumour predisposition syndromes and the accompanying clinical spectrum with respect to tumour type and family history needs separate studies and is outside the scope of this manuscript. We have left this consideration to the expertise of the senior clinical geneticists evaluating the results of the instrument.

The optimal validation of the instrument would be a comparative prospective study in a cohort of newly diagnosed paediatric oncology patients: referrals and reasons for referral using the screening instrument could then be compared to the routine consultation done by an experienced clinical geneticist ('reference standard'). The low incidence of tumour predisposition syndromes requires the recruitment of large numbers of patients for a considerable period of time to perform a study that potentially will yield useful results. This approach was not suitable for an initial, short-term validation. We recognise that the validation cohort is too small to support clinical implementation of the instrument. However, it does show that geneticists using the screening instrument recognise those childhood cancer patients that may have a tumour predisposition syndrome when compared to the reference standard. We can conclude that the geneticists using the instrument to evaluate 
the patient did not miss any significant clues for referral. This supports the design of the aforementioned, subsequent study. A prospective study, in which the feasibility and validity of the final screening instrument will be assessed, is needed to determine the diagnostic value of the instrument and is planned at present.

\section{Conclusion}

We have used a Delphi process to gather expert opinions on manifestations detectable at body surface examination that contribute to the diagnosis of a tumour predisposition syndrome. The value of the assembled expert opinions using the Delphi method is that it reflects consensus in a group of experts on a subject where evidence from the literature is lacking. This study combines data from one of the most used databases in dysmorphology and a major textbook in clinical genetics with the opinion of recognised experts in tumour predisposition syndromes. The results of the overall process formed the basis of a screening form which, when combined with the standardised series of pictures, formed a screening instrument. The screening instrument showed an excellent correlation with the reference standard in a small pilot study. The feasibility and validity of the screening instrument will be evaluated in a subsequent, prospective large study.

\section{Conflict of interest statement}

L.G.B. is an unpaid advisor to the Illumina Corp. and receives in-kind research support for work unrelated to the present manuscript.

\section{Acknowledgements}

The authors would like to thank the parents and their patients for their participation in the validation study. Also, the authors are very grateful to Conny van der Meer and Rogier Kersseboom (Department of Clinical Genetics, Erasmus Medical Centre, Rotterdam, The Netherlands) for their indispensable assistance in the first validation. The authors also thank Richard Heinen and Jeannette van Gelder for sharing their great expertise in building and querying databases and Cor van den Bos for his valuable comments on the manuscript.

This study was funded by the 'Tom Voûte Fund'. LGB is supported by the Intramural Research Program of the National Human Genome Research Institute.

\section{Appendix A. Supplementary data}

Supplementary data associated with this article can be found, in the online version, at http://dx.doi.org/ 10.1016/j.ejca.2013.06.015.

\section{References}

1. Merks JH, Ozgen HM, Koster J, et al. Prevalence and patterns of morphological abnormalities in patients with childhood cancer. JAMA 2008;299:61-9.

2. Merks JH, Caron HN, Hennekam RC. High incidence of malformation syndromes in a series of 1073 children with cancer. Am J Med Genet A 2005;134A:132-43.

3. Merks JH, Ozgen HM, Cluitmans TL, et al. Normal values for morphological abnormalities in school children. Am J Med Genet A 2006;140:2091-109.

4. Mehes K. Malformations in children with cancer. Am J Med Genet A 2006;140:932.

5. Orellana C. Malformation syndromes during cancer in childhood. Lancet Oncol 2005;6:198.

6. Winter RM, Baraitser M. The London dysmorphology database. J Med Genet 1987;24:509-10.

7. Hennekam RCM, Krantz ID, Allanson JE. Gorlin's syndromes of the head and neck. 5th ed. New York, USA: Oxford University Press Inc.; 2010.

8. Allanson JE, Biesecker LG, Carey JC, Hennekam RC. Elements of morphology: introduction. Am J Med Genet A 2009;149A:2-5.

9. Allanson JE, Cunniff C, Hoyme HE, et al. Elements of morphology: standard terminology for the head and face. Am J Med Genet A 2009;149A:6-28.

10. Biesecker LG, Aase JM, Clericuzio C, et al. Elements of morphology: standard terminology for the hands and feet. Am J Med Genet A 2009;149A:93-127.

11. Hennekam RC, Cormier-Daire V, Hall JG, et al. Elements of morphology: standard terminology for the nose and philtrum. Am J Med Genet A 2009;149A:61-76.

12. Hunter A, Frias JL, Gillessen-Kaesbach G, et al. Elements of morphology: standard terminology for the ear. Am J Med Genet A 2009;149A:40-60.

13. Carey JC, Cohen Jr MM, Curry CJ, et al. Elements of morphology: standard terminology for the lips, mouth, and oral region. Am J Med Genet A 2009;149A:77-92.

14. Hall BD, Graham Jr JM, Cassidy SB, Opitz JM. Elements of morphology: standard terminology for the periorbital region. $\mathrm{Am}$ J Med Genet A 2009;149A:29-39.

15. Hsu C, Sandford BA. The Delphi technique: making sense of consensus. Pract Assess Res Eval 2011;12:1-8.

16. Dalkey NC, Helmer O. An experimental application of the Delphi method to the use of experts. Manag Sci 1963;9:458-67.

17. Hobbelen JS, Koopmans RT, Verhey FR, Van Peppen RP, de Bie RA. Paratonia: a Delphi procedure for consensus definition. $J$ Geriatr Phys Ther 2006;29:50-6.

18. McGinnis PQ, Wainwright SF, Hack LM, Nixon-Cave K, Michlovitz S. Use of a Delphi panel to establish consensus for recommended uses of selected balance assessment approaches. Physiother Theory Pract 2010;26:358-73. 